\section{KREATIF}

Jurnal Ilmiah

Prodi Manaiemen Universitas Pamulang
Pamulang ISSN : $2339-0689$, E-ISSN : 2406-8616

J. KREATIF, Vol. 7, No. 2, Desember 2019 (Halaman 10-18)

Tersedia Online di : http://openjournal.unpam.ac.id/index.php/kreatif

\title{
PENGARUH PELATIHAN,DISIPLIN KERJA DAN BUDAYA ORGANISASI TERHADAP KINERJA PEGAWAI PT KERETA API INDONESIA (PERSERO) DAERAH OPERASI 1 JAKARTA
}

\author{
Lidya Pricilla \\ Program Studi Manajemen \\ Dosen Universitas Pamulang \\ dosen02478@unpam.ac.id
}

\begin{abstract}
ABSTRAK
Maksud dari penelitian ini untuk mengkaji serta memahami adakah antara Pelatihan, Disiplin Kerja, Dan Budaya Organisasi pengaruhnya Terhadap Kinerja pegawai PT Kereta Api Indonesia Daerah Operasi 1 Jakarta baik dilihat dari segi secara parsialnya maupun simultannya.

Mekanisme yang mendukung pada penelitian ini yaitu dengan metode asosiatif dengan 128 responden. Teknik yang diperoleh dalam pengumpulan ini data dari kuesioner dengan menganalisis data yakni dengan instrument data, pengujian klasik dan regresi berganda linier.

Hitungan yang didapat dengan nilai $F_{\text {hitung }} 39,099>F_{\text {tabel }} 2,68$. kemudian dapat ditarik kesimpulan bahwa adakah pengaruh positif yang bersignifikan antara Pelatihan, Disiplin Kerja, Budaya Organisasi Terhadap Kinerja Pegawai. Perhitungan hasil analisis regresi linear berganda yang telah ditemukan adalah $\mathrm{Y}=8,889+0.187 \mathrm{X}_{1}+0.167 \mathrm{X}_{2}+0,417 \mathrm{X}_{3}$,
\end{abstract}

Kata Kunci : Pelatihan, Disiplin Kerja, Budaya Organisasi Dan Kinerja

\section{ABSTRACT}

The purpose of this study is to examine and understand whether there is Training, Work Discipline, And Organizational Culture that has an influence on the on Performance of the employees of PT Kereta Api Indonesia Operation area 1 Jakarta both in terms of partial and simultaneous.

The mechanism that supports this research is the associative methods with 128 respondents. The technique obtained in this collection of data from the questionnaire by analyzing data namely instrument data,classical testing, and multiple linear regression.

The results obtained with $F_{\text {arithmetic }} 39,099>F_{\text {table }} 2,68$. Then it can be concluded that is there a significant positive effect between Training, Work Discipline, Organizational Culture Against Employee Performance. The result of multiple linear regression analysis which have been found is $Y=8,889+0,187 X_{1}+0,167 X_{2}+0,417 X_{3}$.

Keywords: Training, Work Discipline, Organizational Culture and Performance

\section{PENDAHULUAN}

\section{A. Latar Belakang}

Transportasi merupakan parameter untuk mengukur lajunya suatu pertumbuhan ekonomi dalam suatu negara. Transportasi juga dapat 
membantu mempermudah mobilitas penduduk dari suatu daerah ke daerah lainnya dengan cepat dan aman. Sehingga banyak perusahaan transportasi yang bersaing menyediakan moda transpotasi untuk masyarakat dengan biaya murah tanpa mengurangi kualitasnya contohnya seperti jasa angkutan kereta api yang saat ini menjadi solusi dari masalah transportasi publik karena moda transportasi publik tersebut dapat berpartisipasi dalam meningkatkan perekonomian dengan dibuktikan dengan Kepemilikan Saham PT Kereta Api Indonesia (Persero) $100 \%$ dimiliki pemerintah. PT Kereta Api Indonesia (Persero) dapat memberikan pelayanan transportasi yang dapat melayani barang dan jasa dengan cara cepat ,mudah dan aman dibandingkan dengan moda transportasi lain yang ada saat ini. Adapun produk dan jasa yang ditawarkan dari PT Kereta Api Indonesia (Persero) yaitu enam bidang pelayanannya terdiri dari : angkutan penumpang, angkutan barang, pengelolaan properti, restoran ,pariwisata kereta api dan distribusi logistik.

Mengawali perubahan tersebut PT Kereta Api Indonesia (Persero) Daerah Operasi 1 jakarta harus melakukan restrukturisasi (penataan kembali) dan reformasi dengan harapan akan adanya perubahan yang berkelanjutan.

Pengelolaan pegawai yang tepat akan menciptakan kinerja pegawai yang tinggi yang nantinya akan mendorong peningkatan kinerjanya. Maka dari itu PT Kereta Api Indonesia (Persero) selalu rutin berkala dalam memberikan pelatihan yang tepat dan sesuai dengan kebutuhan pegawainya karena pengetahuan dan keterampilan pegawainya belum optimal. Hal tersebut bisa terjadi dikarenakan belum efektifnya metode pelatihan yang dilakukan PT Kereta Api Indonesia (Persero) Daerah Operasi 1 Jakarta sehingga masih ada saja kendala-kendala yang harus dihadapi. Seperti salah satunya belum maksimal dalam melakukan tanggung jawab dan tugas sesuai target ditentukan perusahaan sehingga belum terealisasi secara keseluruhan target tersebut. Sehingga hal tersebut berpengaruh terhadap kinerjanya.

Faktor yang dapat berpengaruh tentang kinerja pegawai yaitu disiplin kerja. Kurang disiplin serta tidak taat terhadap aturan yang ada serta norma-norma yang ditetapkan akan berdampak pada penurunan efisiensi dan efektifitas kerja dalam penggunaan sumber dayanya. Sehingga dapat menimbulkan tujuan perusahaan yang tidak tercapai secara keseluruhan baik efektif maupun efisien. Pegawai yang disiplin akan dapat menyelesaikan pekerjaannya sesuai dengan waktu yang telah ditentukan. Seperti apabila pegawai yang tidak masuk kerja tanpa memberikan keterangan dengan jelas terlebih dahulu. Tingkat kehadiran merupakan sebagian faktor yang berpengaruh terhadap penilaian kinerja,baik keterlambatan,tidak hadir dengan sengaja ataupun keterlambatan kerja. Dampak dari berkurangnya disiplin kerja pegawai yang mempengaruhi turunnya produktivitas kerja juga. Menurunya kinerja pegawai menjadi penyebab utama perusahaan dalam menghadapi keterlambatan dalam pencapaian tujuan. Agar dapat meminimalisir agar tidak terjadinya hal yang tidak diinginkan tersebut. Perusahaan harus menetapkan aturan-aturan yang harus dijalankan dan ditaati oleh seluruh pegawai tanpa terkecuali supaya visi dan misi perusahaan dapat 
tercapai. Apabila hal tersebut sudah terealisasi nantinya akan menjadi kebiasaan-kebiasaan yang membawa dampak positif baik untuk perusahaan maupun pegawainya.

Sehingga budaya organisasi dalam suatu perusahaan akan terus menerus dilakukan sosialisasi kepada pegawai. Dengan demikian, perubahan budaya organisasi dapat dilakukan terlebih dahulu melalui pengubahan pola pikir segenap sumber daya manusia didalam organisasi. Meskipun dalam pelayanan belum optimal namun selalu mengembangkan inovasi yang berkelanjutan dan persaingan usaha.

Berdasarkan fenomena yang terjadi tersebut maka penelitian ini dibuat bertujuan agar dapat memahami dan mengerti apakah pelatihan,disiplin kerja dan budaya organisasi berpengaruh positif bersignifikan secara parsial maupun simultan terhadap kinerja.

\section{B. Rumusan}

Adakah antara Pelatihan, Disiplin Kerja, Dan Budaya Organisasi pengaruhnya Terhadap Kinerja pegawai PT Kereta Api Indonesia Daerah Operasi 1 Jakarta baik dilihat dari segi secara parsialnya maupun simultannya?

\section{TINJAUAN PUSTAKA}

\section{A. Teori Pelatihan}

Menurut Mondy (2008:210) "pelatihan merupakan serangkaian aktivitas yang dirancang guna memberi pengetahuan dan keterampilan yang dibutuhkan para pembelajar untuk dapat melaksanakan pekerjaan mereka pada saat ini".

\section{B. Teori Disiplin Kerja}

Menurut Singodimedjo (2012:86) "disiplin adalah sikap kesediaan dan kerelaan seseorang untuk memahami dan mentaati norma-norma peraturan yang berlaku disekitarnya".

C. Teori Budaya Organisasi

Menurut Munandar (2008:263)"budaya organisasi merupakan cara berpikir, berperasaan, dan bereaksi berdasarkan pola-pola tertentu yang ada dalam organisasi atau yang ada pada bagian-bagian organisasi”.

\section{Teori Kinerja}

Menurut Sedarmayanti (2011:260)"Kinerja merupakan terjemahan dari performance yang berarti Hasil kerja seorang pekerja, sebuah proses manajemen atau suatu organisasi secara keseluruhan, dimana hasil kerja tersebut harus dapat ditunjukkan buktinya secara konkrit dan dapat diukur dibandingkan dengan standar yang telah ditentukan".






\section{Kerangka Konseptual}

\section{E. Hipotesis}

Diduga antara Pelatihan, Displin Kerja dan Budaya Organisasi adakah pengaruh yang positif bersignifikan secara simultan dengan kinerja.

\section{METODE PENELITIAN}

\section{Jenis Penelitian}

Penelitian ini berjenis asosiatif. penelitian yang membahas tentang pengaruh dan bagaimana hubungan antar dua atau lebih variabel $\mathrm{x}$ terhadap variabel y. Tujuan dari penelitian ini untuk menjelaskan pengaruh pelatihan, disiplin kerja dan budaya organisasi terhadap kinerja pegawai.

\section{Tempat dan Waktu Penelitian}

Sampel dalam penelitian ini diambil dari populasi berjumlah 128 responden. Terdiri dari divisi SDM \& umun, keuangan, hukum dan sarana.

\section{Metode Analisis Data}

Metode analisis yang digunakan yaitu : uji validitas, uji reliabilitas, uji asumsi klasik, regresi linear berganda, koefisien korelasi,koefisien determinasi dan uji $\mathrm{F}$.

\section{HASIL PENELITIAN DAN PEMBAHASAN}

a. Uji Instrumen Data : Uji Validitas dan Uji Reabilitas

Tabel

Hasil Uji Validitas

\begin{tabular}{|l|c|c|c|c|c|c|}
\hline Per & $\begin{array}{c}\text { Nilai r } \\
\text { hitung } \\
\text { Pelatihan } \\
\left(\mathbf{X}_{\mathbf{1}}\right)\end{array}$ & $\begin{array}{c}\text { Nilai r } \\
\text { hitung } \\
\text { Disiplin } \\
\text { Kerja } \\
\mathbf{X}_{\mathbf{2}}\end{array}$ & $\begin{array}{c}\text { Nilai r hitung } \\
\text { Budaya } \\
\text { Organisasi } \\
\left.\mathbf{( X}_{\mathbf{3}}\right)\end{array}$ & $\begin{array}{c}\text { Nilai } \mathbf{r} \\
\text { hitung } \\
\text { Kinerja } \\
(\mathbf{Y})\end{array}$ & $\begin{array}{c}\text { Nilai } \\
\mathbf{r} \\
\text { tabe } \\
\mathbf{l}\end{array}$ & Ket \\
\hline Per 1 & 0,459 & 0,433 & 0,583 & 0,475 & 0,1736 & Valid \\
\hline Per 2 & 0,545 & 0,732 & 0,490 & 0,533 & 0,1736 & Valid \\
\hline Per 3 & 0,624 & 0,696 & 0,681 & 0,522 & 0,1736 & Valid \\
\hline Per 4 & 0,461 & 0,599 & 0,655 & 0,447 & 0,1736 & Valid \\
\hline Per 5 & 0,536 & 0,625 & 0,729 & 0,708 & 0,1736 & Valid \\
\hline Per 6 & 0,511 & 0,675 & 0,693 & 0,661 & 0,1736 & Valid \\
\hline Per 7 & 0,724 & 0,822 & 0,832 & 0,849 & 0,1736 & Valid \\
\hline Per 8 & 0,490 & 0,793 & 0,838 & 0,844 & 0,1736 & Valid \\
\hline Per 9 & 0,513 & 0,766 & 0,825 & 0,651 & 0,1736 & Valid \\
\hline Per 10 & 0,557 & 0,735 & 0,614 & 0,802 & 0,1736 & Valid \\
\hline Per 11 & - & 0,709 & - & - & 0,1736 & Valid \\
\hline
\end{tabular}

Sumber: Hasil Data Pengolaan menggunakan SPSS 22

Berdasarkan hasil semua item dinyatakan valid dengan $r$ hitung $>r$ tabel 0,1736 pada keseluruhan nilainya. 
Tabel

Hasil Uji Reliabilitas

\begin{tabular}{|l|c|}
\hline \multicolumn{1}{|c|}{ Variabel } & Nilai Cronbach Alpha \\
\hline Pelatihan $\left(\mathrm{X}_{1}\right)$ & 0,721 \\
\hline Disiplin kerja $\left(\mathrm{X}_{2}\right)$ & 0,881 \\
\hline Budaya Organisasi $\left(\mathrm{X}_{3}\right)$ & 0,885 \\
\hline Kinerja $(\mathrm{Y})$ & 0,846 \\
\hline
\end{tabular}

Sumber: Hasil Data Pengolaan menggunakan SPSS 22

Diketahui bahwa nilai standar ukur $>60$ sehingga ketentuannya adalah sangat sesuai dan konstan pada semua jawaban dari responden secara keseluruhan.

b. Uji Asumsi Klasik

1. Uji Normalitas

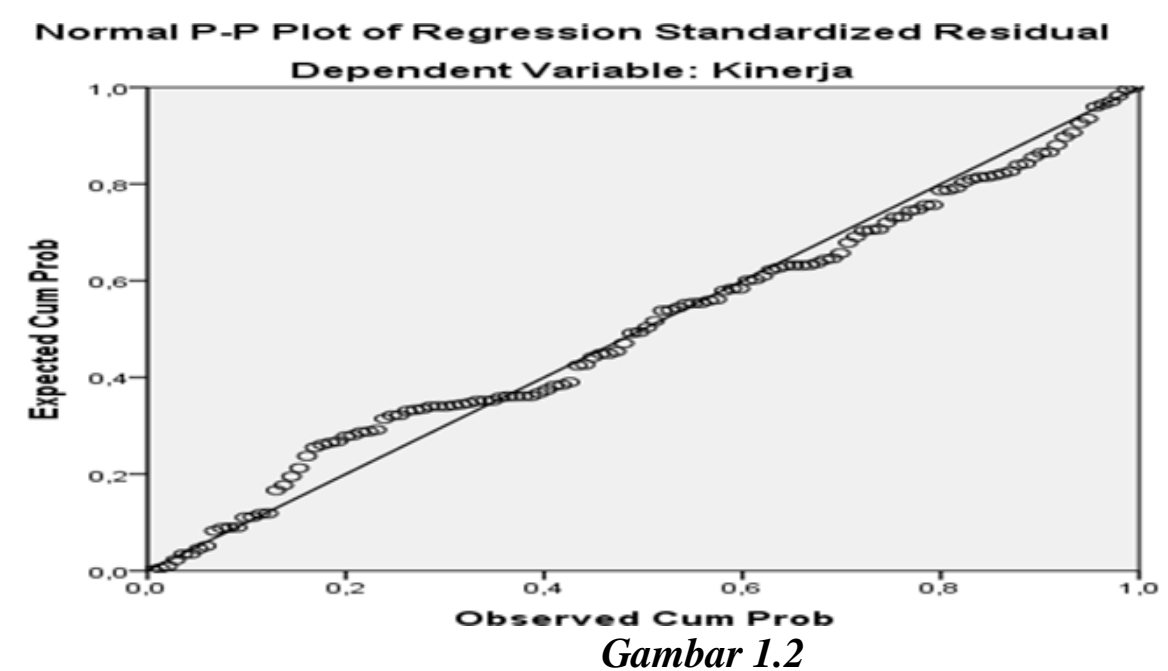

Hasil Data PP Plot Dari Uji Normalitas

Sumber :Hasil Data Pengolaan menggunakan SPSS 22

Diketahui bahwa hasil datanya menunjukkan titik-titik menyebar yang mengikuti garis secara diagonal ,maka uji berdistribusi normal pada penelitian ini.

2. Uji Multikolinearitas

Tabel

Hasil Uji Multikolineritas

\begin{tabular}{|c|c|c|c|}
\hline \multirow{2}{*}{ Model } & \multicolumn{2}{|c|}{ Collinearity Statistics } \\
\cline { 3 - 4 } & (Constant) & Tolerance & VIF \\
\hline \multirow{3}{*}{} & Pelatihan &, 927 & \\
\cline { 2 - 4 } & Disiplin &, 608 & 1,079 \\
\cline { 2 - 4 } & Budaya Organisasi &, 597 & 1,643 \\
\cline { 2 - 4 } & Buy & & 1,674 \\
\hline
\end{tabular}

a. Dependent Variable: Kinerja

Sumber: Hasil Data Pengolaan menggunakan SPSS 22

Melihat Hasil Uji Multikolinearitas diatas pada keseluruhan variabel nilai Tolerance $>0,10$ dan hasil seluruh variabel nilai VIF $>10$ sehingga dinyatakan multikolinieritas tidak terjadi.

3. Uji Heteroskedastisitas 


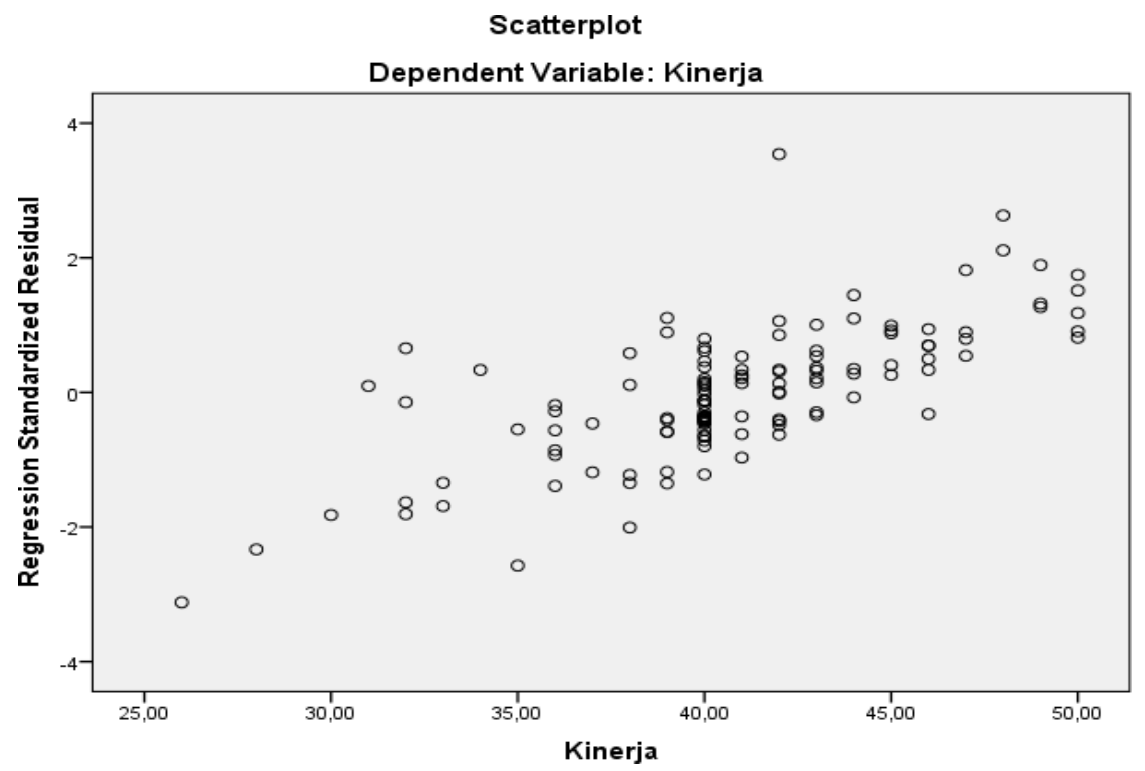

Sumber: Hasil Data Pengolaan menggunakan SPSS 22

Gambar 1.3 Heteroskedastisitas

Diketahui bahwa grafik secara acak arah penyebarannya sehingga titik-titik pola dapat terbentuk sendiri,maka hal tersebut tidak terjadi gejala heteroskedastisitas.

4. Uji Autokorelasi

\section{Tabel}

Model Summary

\begin{tabular}{|c|c|c|c|c|c|c|}
\hline \multirow[b]{2}{*}{ Model } & \multicolumn{5}{|c|}{ Change Statistics } & \multirow[b]{2}{*}{ DurbinWatson } \\
\hline & $\begin{array}{l}\text { R Square } \\
\text { Change }\end{array}$ & F Change & df1 & df2 & $\begin{array}{l}\text { Sig. F } \\
\text { Change }\end{array}$ & \\
\hline 1 & $486^{\mathrm{a}}$ & 39,099 & 3 & 126 &, 000 & 1,814 \\
\hline
\end{tabular}

a. Predictors: (Constant), Budaya Organisasi, Pelatihan, Disiplin

b. Dependent Variable: Kinerja

Sumber: Hasil Data Pengolaan menggunakan SPSS 22

Berdasarkan tabel diatas perolehan nilai sebesar 1,814 dari Dubin

Watsonnya sehingga tidak ada autokorelasi kesimpulan penelitiannya karena pada ketentuannya terletak di angka 1,55-2,46.

\section{c. Regresi}

1. Regresi Linear Berganda dan Hipotesis Parsial

\section{Tabel}

Hasil Perhitungan dari Regresi Linier Berganda

\begin{tabular}{|c|c|c|c|c|c|}
\hline \multirow[t]{2}{*}{ Model } & \multicolumn{2}{|c|}{$\begin{array}{c}\text { Unstandardized } \\
\text { Coefficients }\end{array}$} & \multirow{2}{*}{$\begin{array}{l}\text { Standardized } \\
\text { Coefficients } \\
\text { Beta }\end{array}$} & \multirow[t]{2}{*}{$\mathrm{T}$} & \multirow[t]{2}{*}{ Sig. } \\
\hline & B & $\begin{array}{r}\text { Std. } \\
\text { Error }\end{array}$ & & & \\
\hline (Constant) & 8,889 & 3,289 & & 2,703 &, 008 \\
\hline Pelatihan & ,187 & ,069 &, 182 & 2,721 & ,007 \\
\hline Disiplin & , 167 & ,067 & 207 & 2,505 & ,014 \\
\hline Budaya Organisasi & ,417 & ,073 & ,476 & 5,711 & ,000 \\
\hline
\end{tabular}

a. Dependent Variable: Kinerja

Sumber: Hasil Data Pengolaan menggunakan SPSS 22 


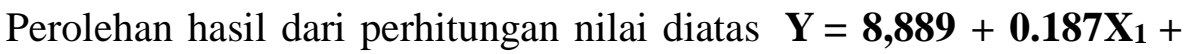
$0.167 X_{2}+0,417 X_{3}$.

1) Berdasarkan hitungan data diatas nilai regresi pelatihan yaitu $0,187 \mathrm{X}_{1}$ dinyatakan naik 1 tingkatan, kemudian kinerja akan ikut meningkat sebesar 0,187 sehingga nilai signifikansi yang didapat $0,007<0,05$ membuktikan bahwa pelatihan kerja berpengaruh positif yang bersignifikan terhadap kinerja.

2) Berdasarkan hitungan data diatas nilai regresi disiplin kerja yaitu $0,167 \mathrm{X}_{2}$ dinyatakan naik 1 tingkatan, kemudian kinerja akan ikut meningkat sebesar 0,167 sehingga nilai signifikansi yang didapat $0,014<0,05$ membuktikan disiplin kerja berpengaruh positif yang bersignifikan terhadap kinerja.

3) Berdasarkan hitungan data diatas nilai regresi budaya organisasi yaitu $0,417 \mathrm{X}_{3}$ dinyatakan naik 1 tingkatan, kemudian kinerja akan ikut meningkat sebesar 0,417 sehingga nilai signifikansi yang didapat $0,000<0,05$ membuktikan budaya organisasi berpengaruh positif yang bersignifikan terhadap kinerja.

2. Koefisien Korelasi

Tabel

Correlations

\begin{tabular}{|c|c|c|c|c|c|}
\hline & & Kinerja & Pelatihan & Disiplin & $\begin{array}{c}\text { Budaya } \\
\text { Organisasi }\end{array}$ \\
\hline \multirow{4}{*}{$\begin{array}{r}\text { Pearson } \\
\text { Correlation }\end{array}$} & Kinerja & 1,000 & 351 &, 543 &, 651 \\
\hline & Pelatihan & ,351 & 1,000 & ,222 & ,259 \\
\hline & Disiplin & ,543 & ,222 & 1,000 & ,622 \\
\hline & \begin{tabular}{|l|} 
Budaya \\
Organisasi
\end{tabular} & ,651 & ,259 & ,622 & 1,000 \\
\hline \multirow{8}{*}{$\begin{array}{r}\text { Sig } \\
\text { (1tailed) }\end{array}$} & Kinerja & . & 000 & ,000 & ,000 \\
\hline & Pelatihan &, 000 & . & ,006 &, 002 \\
\hline & Disiplin &, 000 & ,006 & &, 000 \\
\hline & \begin{tabular}{|l} 
Budaya \\
Organisasi
\end{tabular} & ,000 & ,002 & ,000 & . \\
\hline & Kinerja & 128 & 128 & 128 & 128 \\
\hline & Pelatihan & 128 & 128 & 128 & 128 \\
\hline & Disiplin & 128 & 128 & 128 & 128 \\
\hline & $\begin{array}{l}\text { Budaya } \\
\text { Organisasi }\end{array}$ & 128 & 128 & 128 & 128 \\
\hline
\end{tabular}

Sumber: Hasil Data Pengolaan menggunakan SPSS 22

a) Nilai korelasi pelatihan terhadap kinerja sebesar 0,351 menunjukan bahwa hubungannya rendah.

b) Nilai korelasi disiplin kerja terhadap sebesar 0,543 menunjukan bahwa hubungannya sedang (cukup).

c) Nilai korelasi budaya organisasi terhadap kinerja sebesar 0,651 menunjukan bahwa hubungannya kuat.

\section{Koefisien Determinasi (KD)}

\section{Tabel 1.7}

Hasil Perhitungan Koefisien Determinasi 


\begin{tabular}{|l|c|r|r|r|}
\hline Model & $\mathrm{R}$ & $\mathrm{R}$ Square & Adjusted R Square & $\begin{array}{c}\text { Std. Error of the } \\
\text { Estimate }\end{array}$ \\
\hline 1 &, $697^{\mathrm{a}}$ &, 486 &, 474 & 3,30784 \\
\hline
\end{tabular}

1. Predictors: (Constant), Pelatihan, Disiplin, Budaya

Organisasi

2. Dependent Variable: Kinerja

Sumber: Hasil Data Pengolaan menggunakan SPSS 22

Hasil pengolahaan memperlihatkan sebesar 0,486 untuk nilai $R$ Squarenya dengan artian berpengaruh pada ke tiga variabel yaitu pelatihan ,displin kerja dan budaya organisasi secara simultan hasilnya hanya berkontribusi atas kinerja pegawai (Y) sebesar $48,6 \%$, sebaliknya sebesar $51,4 \%$ sisanya dari variabel lain yang tidak ada kaitannya dalam penelitian.

4. Uji F Simultan

Tabel

Hasil Uji F hitung

\begin{tabular}{|c|c|c|c|c|c|}
\hline Model & $\begin{array}{r}\text { Sum of } \\
\text { Squares }\end{array}$ & Df & $\begin{array}{c}\text { Mean } \\
\text { Square }\end{array}$ & $\mathrm{F}$ & Sig. \\
\hline Regression & 1283,434 & 3 & 427,811 & 39,099 &, 000 \\
\hline Residual & 1356,785 & 126 & 10,942 & & \\
\hline Total & 2640,219 & 127 & & & \\
\hline
\end{tabular}

Sumber: Hasil Data Pengolaan menggunakan SPSS 22

Adanya pengaruh positif yang signifikan dengan hasil $\mathrm{F}$ hitung 39,099>F tabel 3,07 dari sig 0,000<0,05sehingga pada keseluruhan variabel berkaitan secara simultan.

\section{PENUTUP}

\section{A. Kesimpulan}

1. Adanya pengaruh positif yang signifikan antara pelatihan terhadap kinerja pada pegawai PT Kereta Api Indonesia (Persero) Daerah Operasi 1 Jakarta sehingga membuktikan bahwa tingkat pelatihan rendah maka kinerja menurun. Sehingga hal tersebut terjadi karena nilai korelasinya hanya sebesar 0,351 sedangkan besarnya kontribusi pada pelatihan terhadap kinerja hanya senilai $12,3 \%$.

2. Adanya pengaruh positif yang signifikan antara displin kerja terhadap kinerja pada pegawai PT Kereta Api Indonesia (Persero) Daerah Operasi 1 Jakarta sehingga membuktikan bahwa disiplin yang rendah dalam bekerja akan menimbulkan turunnya kinerja. Sehingga terjadi nilai korelasinya sebesar 0,543 sedangkan besarnya kontribusi disiplin kerja terhadap kinerja yakni hanya senilai $29,5 \%$.

3. Adanya pengaruh positif yang signifikan antara Budaya Organisasi terhadap kinerja pada pegawai PT Kereta Api Indonesia (Persero) Daerah Operasi 1 Jakarta sehingga membuktikan tingkat budaya organisasi yang tinggi akan menimbulkan peningkatan pada kinerjanya. Sehingga nilai pada korelasinya sebesar 0,651 besar 
B. Saran

kontribusinya budaya organisasi terhadap kinerja yakni $42,4 \%$.

4. Secara simultan pengaruh pelatihan, displin kerja dan budaya organisasi terhadap kinerja pada pegawai PT Kereta Api Indonesia (Persero) Daerah Operasi 1 Jakarta berpengaruh secara positif yang signifikan. Sehingga didapat besarnya hasil kontribusi secara keseluruhan variabel yang berkaitan sebesar $48,6 \%$.

1. Instruktur pelatihan harus sesuai kebutuhan masing-masing pegawai agar dapat maksimal dalam bekerja.

2. Pergunakanlah waktu dalam bekerja dengan baik sesuai dengan aturan dan norma- norma yang berlaku di perusahaan.

3. Tingkatkan profesionalisme PT Kereta Api Indonesia ( Persero ) sebagai penyedia layanan jasa dan angkutan barang perkeretaapian di Indonesia.

4. Tingkatkan pelayanan dan berikan yang terbaik untuk stakeholders sesuai slogan PT Kereta Api Indonesia " Anda adalah Prioritas Kami”.

\section{DAFTAR PUSTAKA}

Algifari. 2007. Analisis: Teori dan Kasus Solusi. BPFE UGM. Yogyakarta.

Ghozali, Imam. 2009. Aplikasi Analisis Multivariate dengan Program SPSS Semarang, UNDIP.

Mondy R Wayne. 2008. Manajemen Sumber Daya Manusia. Jakarta: Erlangga.

Munandar, Ashar Sunyoto. 2008. Psikologi Industri dan Organisasi. Universitas Indonesia,jakarta.

Soedarmayanti 2011, Build and Develop Leadership And Improve Performance To Achieve Success, first printing, Refika Aditama, Bandung.

Sugiyono(2014). Metode Penelitian Pendidikan Pendekatan Kuantitatif, Kualitatif, dan $R \& D$. Bandung: Alfabeta

Veithzal Rivai. 2008. Manajemen Sumber Daya Manusia Untuk Perusahaan : Dari Teori Ke Praktik. PT. Raja Grafindo Persada, Jakarta. 